\title{
Review
}

\section{Revisiting Sensitization Mechanisms in Cancer Thermochemotherapy: Does the Production of Radicals Hold the Key to Sensitization?}

\author{
HIDEKI MATSUMOTO* \\ Division of Oncology, Biomedical Imaging Research Center, University of Fukui, 23-3 Matsuoka-Shimoaitsuki, \\ Eiheiji-cho, Fukui 910-1193, Japan
}

\begin{abstract}
The mechanism involved in the potentiation of cell killing and antitumor activity which result from combined treatments with hyperthermia and chemotherapeutic drugs is believed to be an increase in DNA damage caused by an increase in drug uptake. These events can be brought about by the disruption of membrane permeability by hyperthermia. It has recently been suggested that the contribution of reactive oxygen species (ROS) to the cytotoxic activity of anti-cancer drugs may be important in combined treatments utilizing hyperthermia and chemotherapeutic drugs. The present review examines the possibility that ROS, generated from chemotherapeutic drugs or by interactions between chemotherapeutic drugs and biomaterials or hyperthermia, may make a major contribution to the potentiation of cell killing and antitumor activity in thermochemotherapy.
\end{abstract}

Key Words: hyperthermia, chemotherapeutic drugs, reactive oxygen species (ROS)

\section{Introduction}

Since the first International Conference for Hyperthermic Oncology was held in Washington DC, USA, in 1975, interest in hyperthermic cancer therapy as a novel modality for cancer therapy has expanded around the world. Although both the number of articles and participants in meetings focusing on hyperthermic cancer therapy increased in the first decade after 1975, interest in hyperthermic cancer therapy was clouded by poor clinical outcomes. A renewed interest in hyperthermic cancer therapy as an adjuvant therapy before and after surgery, and as a combination therapy with radio- and chemo-therapy has been generated by improvements in heating devices, beneficial changes in systems for therapy planning, and by the elucidation of some of the mechanisms involved in cell killing and antitumor effects resulting from heating. Indeed, a reasonable efficacy for hyperthermic cancer therapy using a standard heating device has been demonstrated by local control rates for recurrent breast cancers and melanomas, by survival rates for head and neck cancers, and for glioma and cervical cancers in several phase III clinical trials designed to compare radiotherapy alone to combined treatments using radiotherapy and hyperthermia.

Received 17 January, 2008, Accepted 23 February, 2008. *Corresponding author; Tel, +81-776-61-8333; Fax, +81-776-61-8146 ; e-mail, hidekim@u-fukui.ac.jp

doi : $10.3191 /$ thermalmed.24.13

(C) 2008 Japanese Society for Thermal Medicine 
It has been reported that reactive oxygen species (ROS) and reactive nitrogen species (RNS) are involved in the mechanisms leading to cell killing and antitumor effects produced by chemotherapeutic drugs. Alkylating drugs (cyclophosphamide, melphalan, and BCNU), metal complex compounds (cisplatin and carboplatin), carcinostatic antibiotics (bleomycin, mitomycin $\mathrm{C}$, and adriamycin), anesthetics $^{1)}$, and antioxidants ${ }^{2)}$ have revealed notable cell killing and antitumor effects in combination with hyperthermia. These drugs possess a common characteristic which is the fact that they can generate radicals through interactions with biological materials or hyperthermia (Table I). It has been reported that the production level of radical species increased in patients receiving cancer chemotherapy ${ }^{3)}$. In the present review, thermosensitization mechanisms will be examined from the viewpoint of the production of radicals.

Most anti-cancer drugs which are widely used for cancer patients produce cell killing effects which result from DNA damage induced directly by the drugs themselves. However, several anti-cancer drugs lead to the indirect induction of DNA damage, or to the modification of lipids and proteins by radicals produced from the compounds themselves, and show an ability to stimulate the production of radicals in combined treatments using chemotherapy and hyperthermia.

\section{Alkylating agents}

Alkylating agents demonstrate cell killing and antitumor effects which result from the alkylation of DNA or proteins. Cyclophosphamide and ifosfamide, which belong to the nitrogen mustard class of agents, and ACNU and BCNU of the nitrosourea class, have been well studied. ACNU and BCNU are used for radiochemotherapy after surgery for glioma, because they are able to pass through the blood-brain barrier. The pharmacodynamic action of alkylating agents is independent of the cell cycle phase in cancer cells.

Table I. Anti-cancer drugs that have their cytotoxic activities enhanced by hyperthermia.

\begin{tabular}{cc}
\hline Category & Anti-cancer drug \\
\hline Alkylating agents & Melphalan \\
& Cyclophosphamide \\
Anti-metabolites & BCNU, CCNU \\
Carcinostatic antibiotics & 5 -Fluorouracil \\
\hline & Bleomycin \\
& Peplomycin \\
& Mitomycin C \\
& Adriamycin \\
Metal complexes & Daunorubicin \\
& Actinomycin D \\
\hline
\end{tabular}

These anti-cancer drugs possess a common characteristic: they produce oxygen radicals through interactions with biomaterials and/or hyperthermia. 
Several alkylating agents are involved in the production of radicals ${ }^{4}$. Cyclophosphamide is metabolized into acrolein by cytochrome $\mathrm{P} 450$ in the liver, and acrolein is cytotoxic. In this metabolic process, hydroperoxy or hydroxyethyl radicals $\left(\cdot \mathrm{OOH}\right.$ or $\left.\cdot \mathrm{CH}_{2} \mathrm{CH}_{2} \mathrm{OH}\right)$ are produced by the reaction of cyclophosphamide with $\mathrm{n}-3$ unsaturated fatty acids ${ }^{5}$. These radicals are also produced by the reaction of melphalan, BCNU, or CCNU with unsaturated fatty acids. Furthermore, since BCNU is an inhibitor of glutathione reductase, the generation of ROS by other agents or by hyperthermia seems to be enhanced by $\mathrm{BCNU}^{6}$. Therefore, the production of peroxylipids from the interaction between these radicals in the plasma and mitochondrial membranes with hyperthermia provide a possible mechanism of sensitization in cancer thermochemotherapy (Fig. 1).

A synergistic enhancement of antitumor effects was found in transplanted Fsa-II tumors in the thighs of mice after combined treatment with ifosfamide and hyperthermia ${ }^{7}$, and also in experimental tumors after combined treatment with hyperthermia and $\mathrm{BCNU}$ or $\mathrm{CCNU}^{8)}$. In addition, remarkable therapeutic efficacies were found in patients treated with a combination of alkylating agents and hyperthermia ${ }^{9}$.

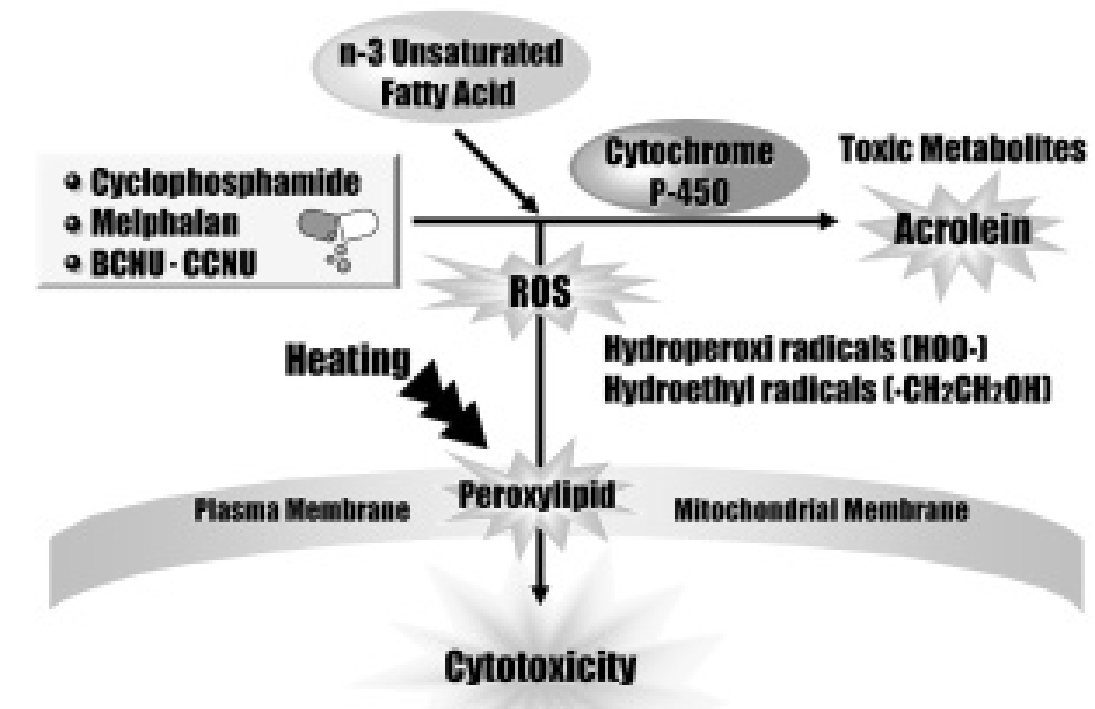

Fig. 1. A possible mechanism for the potentiation of alkylating drug cytotoxicity resulting from the generation of ROS in a combined treatment with hyperthermia.

\section{Anti-metabolites}

Anti-metabolites, analogs of folic and nucleic acid, exhibit cell killing and antitumor effects which result from the inhibition of nucleotide metabolism and/or DNA replication, thus indicating a specificity for cells in S-phase.

5-Fluorouracil (5-FU) acts not only as an anti-metabolite for pyrimidine metabolism, but also as an inducer of ROS. Cardiac toxicity is a serious side effect observed in patients treated with 5-FU ${ }^{10)}$. ROS generation during treatment with 5-FU, leading to lipid peroxidation and cell membrane damage, could 
be one mechanism underlying the toxic effects of 5-FU on the endothelium ${ }^{11)}$. Previous studies on cultured cells, comparing the toxicity of 5-FU on myocytes and endothelial cells from the rat heart, suggested that myocytes are less susceptible than endothelial cells to the direct toxic effect of 5 -FU ${ }^{12)}$. Thus, peroxylipid generated by ROS in the plasma membranes of endothelial cells in tumors can suppress the proliferation of cancer cells through the inhibition of angiogenesis, and can also directly induce cancer cell killing ${ }^{13)}$. Based on these observations, it has been suggested that ROS are involved in the cytotoxicity of 5-FU (Fig. 2). An enhancement of therapeutic efficacy was observed clearly in a combined treatment consisting of radiation and 5-FU ${ }^{14)}$, and also observed in combined treatments consisting of hyperthermia and 5-FU (chemohyperthermic peritoneal perfusion) ${ }^{15}$.

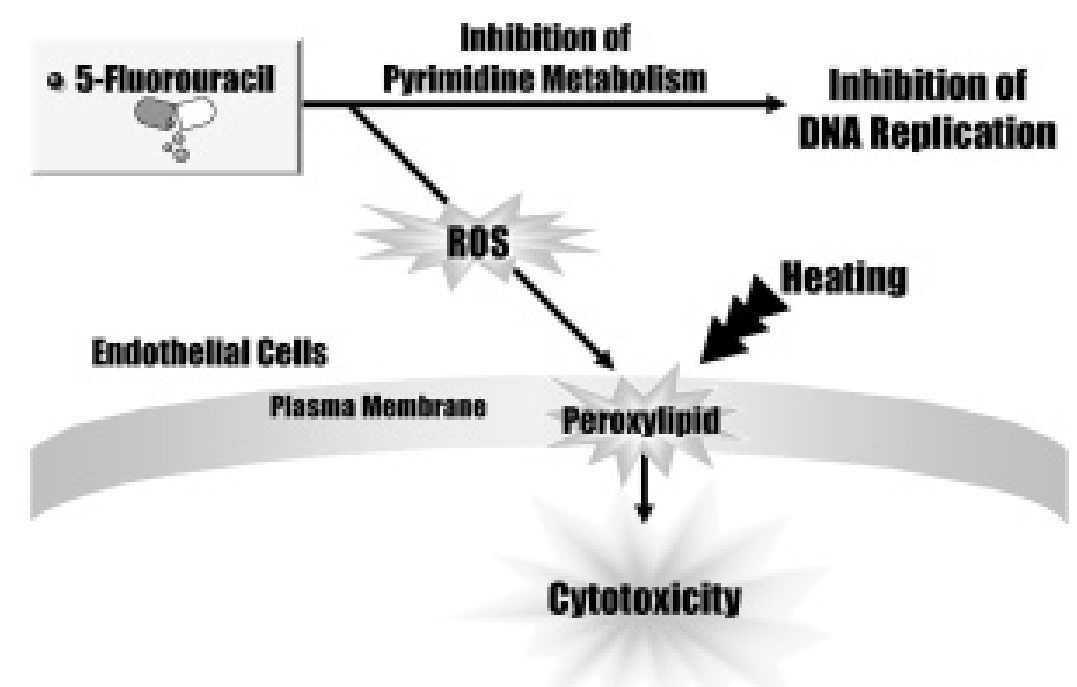

Fig. 2. A possible mechanism for the potentiation of 5-fluorouracil cytotoxicity resulting from the generation of ROS in a combined treatment with hyperthermia.

\section{Carcinostatic antibiotics}

Research into carcinostatic antibiotics was initiated in Japan, and these are now widely used for cancer patients. Carcinostatic antibiotics include carzinophilin, mitomycin $\mathrm{C}$, bleomycin, peplomycin, aclacinomycin A, chromomycin A3, and neocarzinostatin, all of which were discovered in Japan. In particular, mitomycin $\mathrm{C}$ and bleomycin are widely used around the world. Other carcinostatic antibiotics include actinomycin D, daunorubicin, and adriamycin (doxorubicin). Several carcinostatic antibiotics have the ability to produce ROS.

\subsection{Bleomycin and peplomycin}

Bleomycin and peplomycin each have a couple of binding sites for iron ions and DNA. When iron ions bind to specific sites on these drugs and capture oxygen, superoxide radicals $\left(\cdot \mathrm{O}_{2}{ }^{-}\right)$are produced which result in DNA cleavage (Fig. 3). An enhancement of cell killing and antitumor effects was clearly observed in combined treatments using hyperthermia and bleomycin or peplomycin ${ }^{16)}$. 


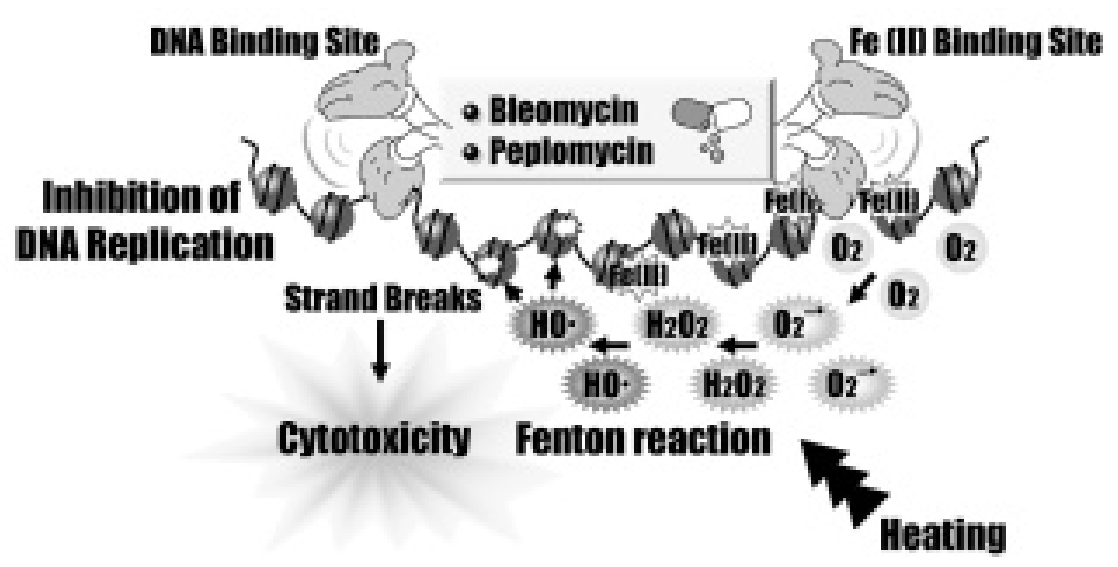

Fig. 3. A possible mechanism for the potentiation of bleomycin/peplomycin cytotoxicity resulting from the generation of ROS in a combined treatment with hyperthermia.

\subsection{Mitomycin $C$}

The cell killing and antitumor effects of mitomycin $\mathrm{C}$ result from several mechanisms via the production of ROS, and include respiratory inhibition, inhibition of DNA replication, and DNA damage. Mitomycin $\mathrm{C}$ has a couple of binding sites for metal ions and DNA. When $\mathrm{Zn}$ (II), $\mathrm{Cu}$ (II), $\mathrm{Mn}$ (II), Cd (II), or Au (III) ions bind to the metal ion binding site in the drug, an irreversible complex (mitomycin C-Metal ion-DNA complex) is formed resulting in the inhibition of DNA replication (Fig. 4). In particular, $\mathrm{Zn}$ (II), $\mathrm{Cu}$ (II), and $\mathrm{Mn}$ (II) ions are highly effective. The induction of DNA damage by mitomycin $\mathrm{C}$ requires the protein to be activated by 1 or 2 electron reductions. Activated mitomycin $\mathrm{C}$ becomes a semiquinone or hydroquinone which reacts with oxygen molecules and produces ROS. These reaction processes are evoked in the mitomycin C-metal ion-DNA complex, and consequently DNA damage is induced by hydroxyl radicals $(\cdot \mathrm{OH})$ produced through the Fenton reaction ${ }^{17}$.

The cell killing effect of hyperthermia was enhanced by the simultaneous administration of mitomycin C in human non-small-cell lung carcinoma H1299 cells, and this enhancement was independent of the $p 53$ status of the cells ${ }^{18}$. In spite of the requirement for oxygen in the production of hydroxyl radicals from mitomycin $\mathrm{C}$, the cell killing effect of hyperthermia was further enhanced by the administration of mitomycin $\mathrm{C}$ under hypoxic conditions ${ }^{19)}$. This suggests that the changes in the intracellular microenvironment by hyperthermia affect the production of ROS by mitomycin C.

\subsection{Anthracycline carcinostatic antibiotics}

Some of the earliest studies describing the possible mechanisms of action of anthracyclines focus on the capacity of these drugs to inhibit DNA replication and RNA transcription caused by drug binding to DNA ${ }^{20}$. In particular, the inhibition of DNA topoisomerase II may be most closely associated with the lethal effects of anthracyclines in cancer cells and tumors. On the other hand, anthracycline carcinostatic antibiotics such as adriamycin and daunomycin have been shown to induce the generation of $\operatorname{ROS}^{21}$. The quinone structure in these drugs acts as an electron acceptor in reactions catalyzed by 


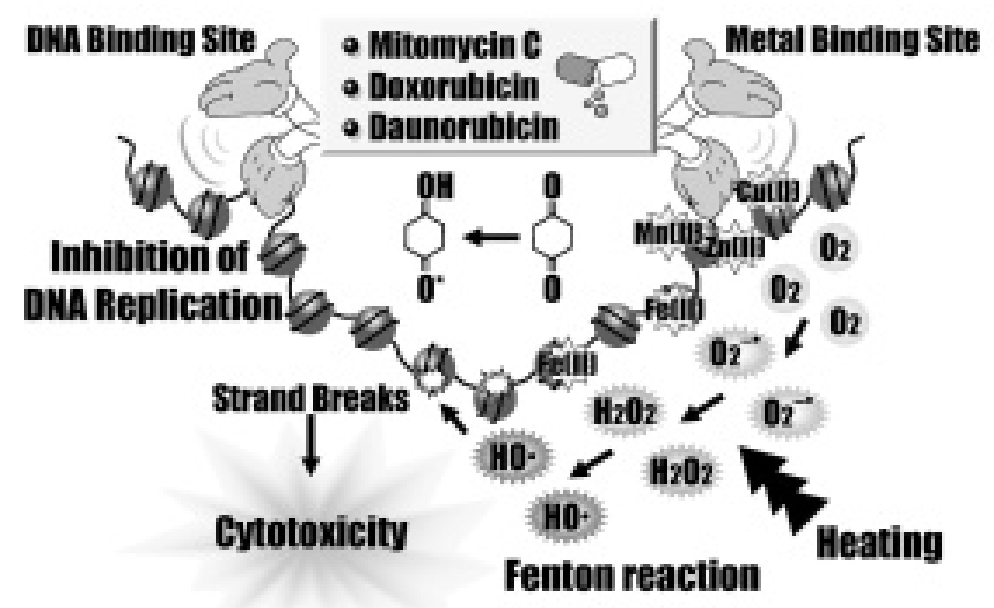

Fig. 4. A possible mechanism for the potentiation of anthracycline carcinostatic antibiotic cytotoxicity resulting from the generation of ROS in a combined treatment with hyperthermia.

oxoreductive enzymes including cytochrome P-450 reductase, NADH dehydrogenase, and xanthine oxidase $^{22)}$. When the quinones capture free electrons, they are reduced by one or two electrons, and can be converted into semiquinone radicals. The cell killing and antitumor effects of anthracyclines are believed to be caused by the reductive metabolic activation of these drugs into reactive intermediates including semiquinone free radicals ${ }^{23)}$. The semiquinone form of these drugs rapidly autoxidizes and reduces molecular oxygen into the superoxide anion radical $\left(\cdot \mathrm{O}_{2}{ }^{-}\right)$and subsequently into other partially reduced species of oxygen, including hydrogen peroxide $\left(\mathrm{H}_{2} \mathrm{O}_{2}\right)$ and hydroxyl radicals $(\cdot \mathrm{OH})$ through the Fenton reaction in an antibiotic-metal ion-DNA complex ${ }^{24)}$. These ROS from anthracycline antibiotics induce DNA damage ${ }^{25)}$ (Fig. 4). However, unresolved questions remain of whether free radicals are generated at clinically relevant concentrations of anthracyclines and at normal (i.e. hypoxic) oxygen tension in cancer cells, and whether such free radicals could be responsible for anthracycline toxicity to the tumor.

The extent of potentiation of cell killing and antitumor effects caused by combined treatments of hyperthermia and adriamycin seems to depend on the temperature and period of heating, the type of cancer cells used in the experiments, and the type of tumors exposed to the treatments. Although a synergistic enhancement of thermosensitivity was induced by a combined treatment consisting of hyperthermia at $43^{\circ} \mathrm{C}$ and adriamycin in Chinese hamster HA-1 cells, only additive effects were found in prolonged treatments ${ }^{26)}$. A stimulated thermotolerance was induced by a combined treatment with hyperthermia at $43^{\circ} \mathrm{C}$ and adriamycin, however, suggesting that the combined treatment may stimulate the induction of $\mathrm{Hsp} 70^{27,28)}$. Collectively, these observations suggest that the synergistic enhancement of thermosensitivity in cancer cells by a combined treatment of hyperthermia and anthracyclines can be found when semiquinone radicals and ROS are generated effectively and occur in addition to the cell killing and antitumor effects caused by binding of the drugs to DNA. 


\section{Alkaloid agents from plants}

Several basic nitrogen compounds exist in plant tissues. These are collectively called plant alkaloids. Some alkaloids have cell killing and antitumor effects and they are widely used as cancer chemotherapeutic drugs. The cell killing and antitumor effects are believed to be due to the inhibition of cell division through the suppression of the formation of spindle fibers, and of the depolymerization of spindle fibers. Therefore, these drugs affect specifically cells in $\mathrm{M}$ phase.

\subsection{Vinca alkaloids}

Vinblastine and vincristine belong in this classification. These drugs block cell division through inhibition of the formation of spindle fibers made from microtubules by binding to tubulin. An enhancement of cell killing effects produced by interactive effects between these drugs and endogenous and exogenous cis-unsaturated fatty acids from both the n-6 and n-3 series was found to occur in human cervical carcinoma cells ${ }^{29}$. The enhancement of cell killing effects by a combined treatment of hyperthermia with these drugs was also found in malignant glioma cells ${ }^{30}$. However, a relationship between the enhanced cytotoxicity and radical generation has not been demonstrated yet.

\subsection{Taxane}

Paclitaxel belongs in this classification. Paclitaxel blocks cell division through the stabilization of microtubules by the stimulation of the polymerization of tubulin. Although paclitaxel itself has no capacity to generate radicals, the stimulation of ROS generation by treatment with paclitaxel was found to occur in human neutrophils ${ }^{31)}$, suggesting that the antitumor effects of paclitaxel can be enhanced by the stimulation of ROS generation in lymphocytes which invade tumors.

\subsection{Etoposide (VP-16)}

Etoposide is an anti-cancer drug which is a specific inhibitor of DNA topoisomerase II, and topoisomerase II modifies DNA topology in an ATP-dependent manner. This allows it to cleave, rewind, and rejoin DNA double strands repeatedly. The antitumor activity of etoposide has been suggested to result from a covalent DNA topoisomerase II-DNA complex formed between the drug and the enzyme, which in turn produces double-strand DNA breaks in tumor cells ${ }^{32)}$. In addition, the dimethoxyphenol ring of etoposide has been implicated in cytotoxicity by leading to metabolic alterations of dihydroxy and $o$-quinone derivatives catalyzed by either cytochrome P-450s, peroxidases, or tyrosinase. Dihydroxy-etoposide promotes DNA damage in the presence of $\mathrm{Cu}$ (II) ions, indicating that hydroxyl radicals $(\cdot \mathrm{OH})$ are responsible for the DNA damage. Hydroxyl radicals $(\cdot \mathrm{OH})$ can be generated during redox-dependent complex formation between $\mathrm{Cu}$ (II) and etoposide in the presence of molecular oxygen $\left(\mathrm{O}_{2}\right)$, and it has been suggested that the hydroxyl radicals $(\cdot \mathrm{OH})$ participate in the formation of single- and double-strand breaks in $\mathrm{DNA}^{33)}$ (Fig. 5). Enhanced thermosensitivity in combined treatments with hyperthermia and etoposide was observed in human colorectal cancer cells ${ }^{34)}$, suggesting that the generation of ROS may contribute to the potentiation of cell killing and antitumor effects in addition to the drug's effect on DNA topoisomerase II. 


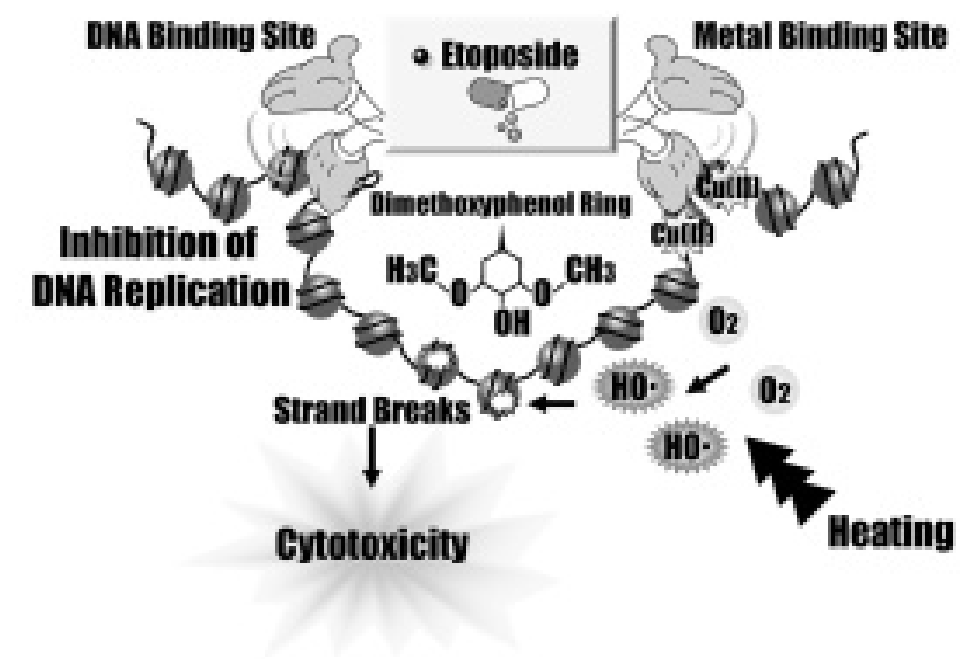

Fig. 5. A possible mechanism for the potentiation of etoposide cytotoxicity by the generation of ROS resulting from a combined treatment with hyperthermia.

\section{Metal complex compounds}

Chemical compound bound ligands around metal ions are collectively called metal complex compounds. The platinum-coordination complexes cisplatin (CDDP) and carboplatin (CBDCA) are potent anti-cancer chemotherapeutic drugs which exhibit a broad spectrum of activity against solid tumors. Carboplatin (CBDCA) has been introduced into clinical practice to overcome some of the toxic effects of cisplatin (CDDP) ${ }^{35,36)}$. The cytotoxic effects of cisplatin (CDDP) and carboplatin (CBDCA) result primarily from their interaction with cellular DNA, since these compounds form inter- and intra-strand crosslinks and DNA-protein crosslinks ${ }^{37}$. It has been shown that these effects are mediated by the formation of common intermediate species, i.e. aquation products, in which the departing ligands, two chlorides and cyclobutanedicarboxylatochelate in cisplatin (CDDP) and carboplatin (CBDCA), respectively, are substituted by water $^{38)}$. Recently, in addition to such cytotoxicity, the anti-cancer activities of cisplatin (CDDP) and carboplatin (CBDCA) have been associated with either the generation of ROS through binding to DNA, or with the stimulation of ROS generation in lymphocytes invading the tumors ${ }^{39}$.

The most likely explanation, including the mechanism of ROS generation by a drug-DNA interaction, is as follows ${ }^{40)}$ (Fig. 6) :

1) $\cdot \mathrm{O}_{2}{ }^{-}$is produced when solubilized molecular oxygen gains a single electron released by the drug-DNA interaction;

2) $\mathrm{H}_{2} \mathrm{O}_{2}$ is produced by a dismutation of $\cdot \mathrm{O}_{2}{ }^{-}$ $\left(2 \cdot \mathrm{O}_{2}{ }^{-}+2 \mathrm{H}^{+} \rightarrow \mathrm{H}_{2} \mathrm{O}_{2}+\mathrm{O}_{2}\right)$;

3) $\cdot \mathrm{OH}$ is produced by the Fenton reaction, probably in the presence of $\mathrm{Fe}$ (II) in the cytosol or chromatin

$\left(\mathrm{H}_{2} \mathrm{O}_{2}+\mathrm{Fe}(\mathrm{II}) \rightarrow \cdot \mathrm{OH}+\mathrm{OH}^{-}+\mathrm{Fe}(\mathrm{II})\right)$;

4) Single or double strand breaks in DNA are evoked by $\cdot \mathrm{O}_{2}{ }^{-}$and $\bullet \mathrm{OH}$. 
In addition, the generation of ROS by interactions between these drugs and DNA is stimulated by the depletion of intracellular glutathione through crosslinking between the drugs and proteins ${ }^{41}$.

There are many reports regarding the potentiation of cell killing and antitumor activity of hyperthermia by cisplatin (CDDP) and carboplatin (CBDCA $)^{42-44}$. The mechanisms involved in the potentiation produced by a combined treatment consisting of hyperthermia and these drugs are believed to be related to an increase in drug uptake due to alterations of membrane permeability, and in an inhibition of the enzymes involved in the nucleotide excision repair of the drug-DNA complexes. Moreover, it has been suggested that hyperthermic stimulation of ROS generation in the drug-DNA complexes is also associated with the potentiation of cell killing and antitumor activity resulting from combined treatments of hyperthermia and these drugs ${ }^{45)}$.

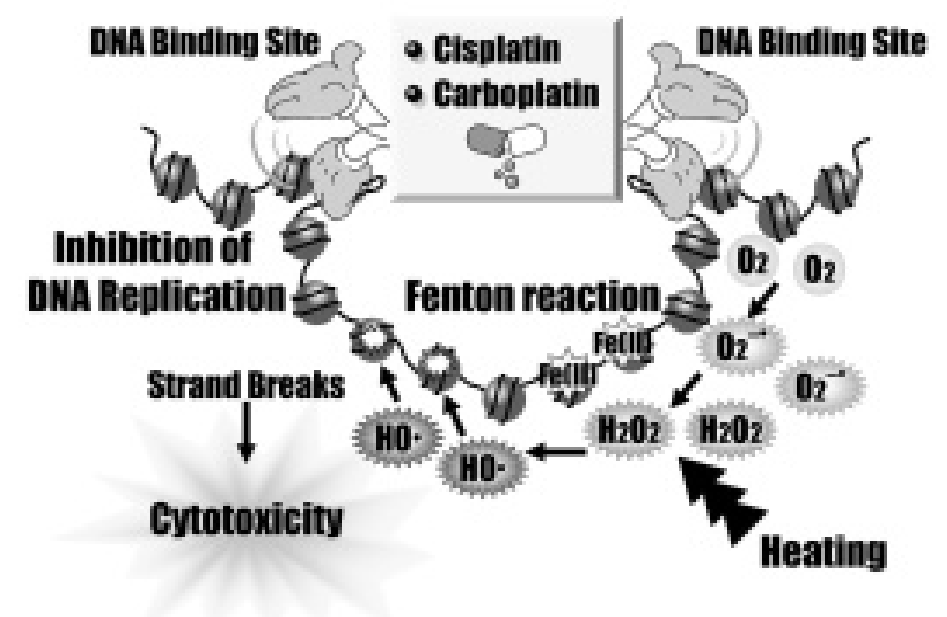

Fig. 6. A possible mechanism for the potentiation of metal complex compound cytotoxicity resulting from the generation of ROS in a combined treatment with hyperthermia.

\section{Other anti-cancer drugs}

Tirapazamine (3-amino-1,2, 4-benzotriazine 1,4-dioxide, SR-4233, TPZ) is a new anti-cancer drug which produces a specific activity in cells in the presence of low oxygen tensions. The mechanism involved in the preferential toxicity of tirapazamine in hypoxic cells is the result of an enzymatic reduction which adds an electron to the tirapazamine molecule converting it into a highly reactive radical. This radical causes cell killing by producing DNA damage leading to chromosomal aberrations. However, in the presence of oxygen, the radical is converted to nontoxic tirapazamine, suggesting a specificity of tirapazamine for targeting only hypoxic tumor cells but not aerobic cells in normal tissues ${ }^{46)}$.

Although clinical trials of combined treatments using radiation or cisplatin and tirapazamine are currently underway ${ }^{47,48)}$, current reports concerning a combined treatment of hyperthermia and tirapazamine are limited to experimental data. Synergistic enhancement of thermosensitivity was observed after a combined treatment with hyperthermia at $42^{\circ} \mathrm{C}$ and $43^{\circ} \mathrm{C}$ with tirapazamine in murine 
Fsa-IIC cells, and a synergistic potentiation of antitumor effects was observed after a combined treatment with hyperthermia at $43^{\circ} \mathrm{C}$ and tirapazamine in transplanted tumors composed of murine Fsa-IIC cells ${ }^{49)}$. Even combined treatments of hyperthermia at $40^{\circ} \mathrm{C}$ with tirapazamine showed an enhancement of cell killing activity in human lingual cancer cells ${ }^{50}$. Tirapazamine is the first anti-cancer drug reported to cause DNA damage by radicals under hypoxic conditions.

The possibility that ROS generated from anti-cancer drugs contributes to the cell killing and antitumor activities of these drugs was discussed in this review (Fig. 7). Further developments and studies of combined treatments with hyperthermia and anti-cancer drugs will hopefully bring about improvements and advances in the results delivered by hyperthermic cancer therapy.

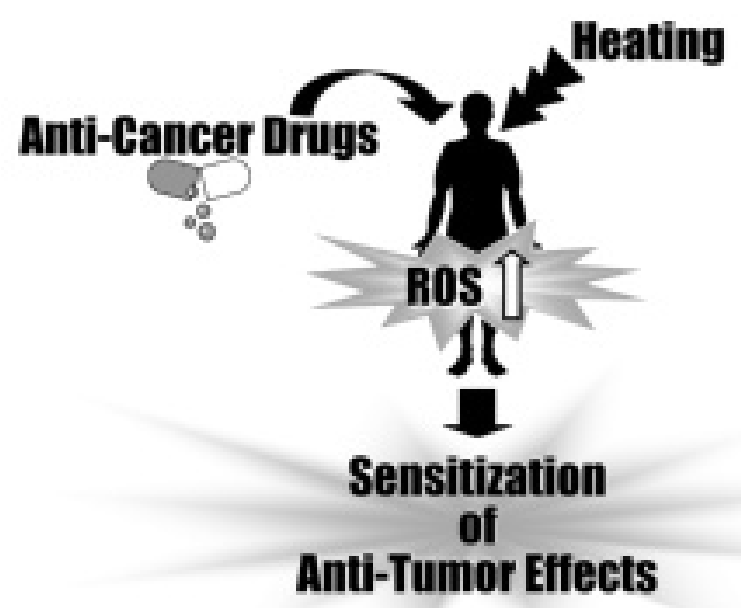

Fig. 7. Summary of the present review.

\section{Acknowledgement}

The author wishes to thank the Chief Editor, Dr. Akihisa Takahashi for his invitation to write this review. This work was supported in part by a Grant-in-Aid for Scientific Research from the Ministry of Education, Culture, Sports, Science and Technology of Japan.

\section{References}

1) Arai Y., Kondo T., Tanabe K., Zhai Q.-L., Li F.-J., Ogawa R., Li M., Kasuya M.: Enhancement of hyperthermia-induced apoptosis by local anesthetics on human histocytic lymphoma U937 cells. J Biol Chem, 277 : 18986-18993, 2002.

2) Cui Z.-G., Kondo T., Matsumoto H. : Enhancement of apoptosis by nitric oxide released from $\alpha$-phenyl-tert-butyl nitrone under hyperthermic conditions. J Cell Physiol, 206 : 468-476, 2006.

3) Sangeetha P., Das U.N., Koratkar R., Suryaprabha P.: Increase in free radical generation and lipid peroxidation following chemotherapy in patients with cancer. Free Radic Biol Med, 8 : 15-19, 1990. 
4) Lamson D.W., Brignall M.S. : Antioxidants in cancer therapy; their actions and interactions with oncologic therapies. Altern Med Rev, 4 : 304-329, 1999.

5) Conklin K.A. : Dietary polyunsaturated fatty acids : impact on cancer chemotherapy and radiation. Altern Med Rev, 7: 4-21, 2002.

6) Coleman J.B., Casini A.F., Serroni A., Farber J.L. : Evidence for the participation of activated oxygen species and the resulting peroxidation of lipids in the killing of cultured hepatocytes by aryl halides. Toxicol Appl Pharmacol, 105 : 393-402, 1990.

7) Kuroda M., Urano M., Reynolds R. : Thermal enhancement of the effect of ifosfamide against a spontaneous murine fibrosarcoma, Fsa-II. Int J Hyperthermia, 13 : 125-131, 1997.

8) Bull J.M., Cronau L.H., Newman B.M., Jabboury K., Allen S.J., Ohno S., Smith T., Tonnesen A.S. : Chemotherapy resistant sarcoma treated with whole body hyperthermia (WBH) combined with 1-3-bis (2-chloroethyl)-1-nitrosourea (BCNU). Int J Hyperthermia, 8: 297-304, 1992.

9) Robins H.I., Rushing D., Kutz M., Tutsch K.D., Tiggelaar C.L., Paul D., Spriggs D., Kraemer C., Gillis W., Feierabend C., Arzoomanian R.Z., Longo W., Alberti D., d'Oleire F., Qu R.P., Wilding G., Stewart J.A.: Phase I clinical trial of melphalan and 41.8 degrees $\mathrm{C}$ whole-body hyperthermia in cancer patients. J Clin Oncol, 15 : 158-164, 1997.

10) Kinhult S., Albertsson M., Eskilsson J., Cwikiel M. : Effects of probucol on endothelial damage by 5-fluorouracil. Acta Oncol, 42 : 304-308, 2003.

11) Cwikiel M., Eskilsson J., Albertsson M., Stavenow L.: The influence of 5-fluorouracil and nethotrexate on vascular endothelium. An experimental study using endothelial cells in the culture. Ann Oncol, 7 : 731-737, 1996.

12) Wenzel D.G., Cosma G.N. : A model system for measuring comparative toxicities of cardiotoxic drugs with cultured rat heart myocytes, endothelial cells and fibroblasts. I. Emetine, chloroquine and metronidazole. Toxicology, 33 : 103-115, 1984.

13) Das U.: A radical approach to cancer. Med Sci Monit, 8: RA79-92, 2002.

14) Ishida K., Ando N., Yamamoto S., Ide H., Shinoda M. : Phase II study of cisplatin and 5-fluorouracil with concurrent radiotherapy in advanced squamous cell carcinoma of the esophagus : a Japan Esophageal Oncology Group (JEOG)/ Japan Clinical Oncology Group trial (JCOG9516). Jpn J Clin Oncol, 34 : 615-619, 2004.

15) Verwaal V.J., van Tinteren H., van Ruth S., Zoetmulder F.A.N. : Predicting the survival of patients with peritoneal cercinomatosis of colorectal origin treated by aggressive cytoreduction and hyperthermic intraperitoneal chemotherapy. Br J Surg, 91: 739-746, 2004.

16) Shioura H., Hayashi S., Matsumoto H., Kitai R., Ohtsubo T., Nishida T., Zhang S.W., Yoshida M., Ishii Y., Kano E. : The effects of combined treatments with low hyperthermia and bleomycin on survivals of murine L cells. J Exp Clin Cancer Res, 16: 147-152, 1997.

17) Bolzan A.D., Bianchi M.S. : Genotoxicity of streptonigrin : a review. Mutat Res, 488 : 25-37, 2001.

18) Jin Z.H., Matsumoto H., Hayashi S., Hatashita M., Ohtsubo T., Shioura H., Kitai R., Kano E. : p53-independent thermosensitization by mitomycin $\mathrm{C}$ in human non-small- cell lung cancer cells. Int J Radiat Oncol Biol Phys, 59 : 852-860, 2004.

19) Teicher B.A., Kowal C.D., Kennedy K.A., Sartorelli A.C. : Enhancement by hyperthermia of the in vitro cytotoxicity of mitomycin C toward hypoxic tumor cells. Cancer Res, 41 : 1096-1099, 1981.

20) Gewirtz D.A. : A critical evaluation of the mechanisms of action proposed for the antitumor effects of the anthracycline antibiotics adriamycin and daunorubicin. Biochem Pharmacol, 57 : 727-741, 1999.

21) Sinha B.K. : Free radicals in anticancer drug pharmacology. Chem Biol Interact, 69 : 293-317, 1989.

22) Doroshow J.H.: Anthracycline antibiotics - stimulated superoxide, hydrogen peroxide and hydroxyl radical production by NADH-dehydrogenase. Cancer Res, $43:$ 4543-4551, 1983. 
Thermal Med. 24〔1]: 2008

23) Sato S., Iwaizumi M., Handa K., Tamura Y. : Electron spin resonance study on the mode of generation of free radicals by daunomycin, adriamycin and carboquinone in NAD (P) H-microsome system. Gann, 68 : 603-608, 1977.

24) Doroshow J.H. : Anthracycline antibiotics - stimulated superoxide, hydrogen peroxide and hydroxyl radical production by NADH-dehydrogenase. Cancer Res, 43 : 4543-4551, 1983.

25) Jung K., Reszka R. : Mitochondria as subcellular targets for clinically useful anthracyclines. Adv Drug Deliv Rev, 49 : 87-105, 2001.

26) Hahn G.M., Strande D.P. : Cytotoxic effects of hyperthermia and adriamycin on Chinese hamster cells. J Natl Cancer Inst, 57 : 1063-1067, 1976.

27) Hayashi S., Kano E., Tsuji K., Furukawa-Furuya M., Yoshikawa S., Hatashita M., Matsumoto H., Jin Z.H., Ohtsubo T., Kitai R. : Modification of thermosensitivity and chemosensitivity induced by combined treatments with hyperthermia and adriamycin. Int J Mol Med, 8: 417-422, 2001.

28) Ohtsubo T., Kano E., Ueda K., Matsumoto H., Saito T., Hayashi S., Hatashita M., Jin Z., Saito H. : Enhancement of heat-induced heat shock protein (hsp) 72 accumulation by doxorubicin (Dox) in vitro. Cancer Lett, 159: 49-55, 2000.

29) Das U.N. : Gamma-linolenic acid, arachidonic acid, and eicosapentaenoic acid as potential anticancer drugs. Nutrition, 6 : 429-434, 1990.

30) Watanabe M., Tanaka R., Hondo H., Kuroki M. : Effects of antineoplastic agents and hyperthermia on cytotoxicity toward chronically hypoxic glioma cells. Int J Hyperthermia, 8 : 131-138, 1992.

31) Wiles M.E., Dykens J.A., Wright C.D. : Human neutrophil (PMN) oxygen radical production and the cytoskeleton. Life Sci, 57 : 1533-1546, 1995.

32) Kagan V.E., Yalowich J.C., Day B.W., Goldman R., Gantchev T.G., Stoyanovsky D.A. : Ascorbate is the primary reductant of the phenoxyl radical of etoposide in the presence of thiols both in cell homogenates and in model systems. Biochemistry, 33 : 9651-9660, 1994.

33) Tawa R., Gao D., Takami M., Imakura Y., Lee K.-H., Sakurai H. : Binding affinity of Cu (II) - VP-16 (etoposide) complex and its analogues to DNA and hydroxyl radical generation during DNA strand breaks. Bioorg Med Chem, 6 : 1003-1008, 1998.

34) Hirohashi Y., Hidaka K., Sato S., Kuwano M., Kohno K., Hisatsugu T. : Biomodulation by hyperthermia of topoisomerase II-targeting drugs in human colorectal cancer cells. Jpn J Cancer Res, 86 : 1097-1105, 1995.

35) Krakoff I.H. : Nephrotoxicity of cis-dichloro-diamineplatinum (II). Cancer Treat Rep, 63 : 1523-1525, 1979.

36) Calvert A.H., Harland S.J., Newell D.R., Siddik Z.H., Jones A.C., McElwain T.J., Rajn S., Wiltshow E., Smith I.E., Baker J.M., Peckham M.J., Harrap K.R. : Early clinical studies with cis-diammine- (1,1-cyclobutanedicarboxylato) platinum (II). Cancer Chemother Pharmacol, 9 : 140-147, 1982.

37) Chu G. : Cellular responses to cisplatin. J Biol Chem, 269: 787-790, 1994.

38) Knox R.J., Friedlos F., Lydall D.A., Roberts J.J. : Mechanisms of cytotoxicity of anticancer platinum drugs : evidence that cis-diamminedichloroplatinum (II) and cis-diammine-(1,1-cyclobutanedicarboxylato) platinum (II) differ only in the kinetics of their interaction with DNA. Cancer Res, 46: 1972-1979, 1986.

39) Fumarulo R., Riccardi S., Restaino A., Giordano D. : Effect of cisplatin on the oxidative metabolism of polymorphonuclear leukocytes in cancer patients. Tumori, 70: 227-229, 1984.

40) Masuda H., Tanaka T., Takahama U. : Cisplatin generates superoxide anion by interaction with DNA in a cell-free system. Biochem Biophys Res Commun, 203 : 1175-1180, 1994.

41) Miyajima A., Nakashima J., Yoshioka K., Tachibana M., Tazaki H., Murai M. : Role of reactive oxygen species in cis-dichlorodiammineplatinum-induced cytotoxicity on bladder cancer cells. Br J Cancer, 76 : 206-210, 1997.

42) Ohtsubo T., Saito H., Tanaka N., Matsumoto H., Sugimoto C., Saito T., Hayashi S., Kano E. : Enhancement of cisplatin sensitivity and platinum uptake by $40^{\circ} \mathrm{C}$ hyperthermia in resistant cells. Cancer Lett, 119: 47-52, 1997.

43) Matsumoto H., Hayashi S., Shioura H., Ohtsubo T., Kitai R., Ohnishi K., Hayashi N., Ohnishi T., Kano E.: 
Suppression of heat-induced HSF activation by CDDP in human glioblastoma cells. Int J Radiat Oncol Biol Phys, 41 : 915-920, 1998.

44) Ohtsubo T., Kano E., Hayashi S., Jin Z.H., Hatashita M., Matsumoto H., Saito H. : In vitro effects of hyperthermia combined with chemotherapeutic agents. Jpn J Hyperthermic Oncol, 16 : 143-151, 2000.

45) Masuda H., Tanaka T., Matsushima S. : Hyperthermic enhancement of cisplatin-induced generation of active oxygen radicals in a cell-free system. Anticancer Res, 18 : 1473-1477, 1998.

46) Brown J.M. : The hypoxic cell : a target for selective cancer therapy-eighteenth Bruce F. Cain Memorial Award lecture. Cancer Res, 59: 5863-5870, 1999.

47) Craighead P.S., Pearcey R., Stuart G.A. : Phase I/II evaluation of tirapazamine administered intravenously concurrent with cisplatin and radiotherapy in women with locally advanced cervical cancer. Int J Radiat Oncol Biol Phys, 48 : 791-795, 2000.

48) Rischin D., Peters L., Hicks R., Hughes P., Fisher R., Hart R., Sexton M., D’Costa I., von Roemeling R. : Phase I trial of concurrent tirapazamine, cisplatin, and radiotherapy in patients with advanced head and neck cancer. J Clin Oncol, 19: $535-542,2001$.

49) Herman T.S., Teicher B.A., Coleman C.N. : Interaction of SR-4233 with hyperthermia and radiation in the FSaIIC murine fibrosarcoma tumor system in vitro and in vivo. Cancer Res, 50: 5055-5059, 1990.

50) Masunaga S., Ono K., Takahashi A., Ohnishi K., Ohnishi T., Suzuki M., Nagata K., Kinashi Y., Nagasawa H., Uto Y., Hori H. : Usefulness of combined treatment with mild temperature hyperthermia and/or tirapazamine in the treatment of solid tumors: its independence of p53 status. Cancer Sci, 94: 125-133, 2003. 